\title{
Violência e Vulnerabilidade: Espaços Vivenciados na Unidade de Internação Socioeducativa para Adolescentes em Porto Vellho-RO
}

\author{
Violence and Vulnerability: Spaces Experienced in Socio-Educational \\ Juvenile Units in Porto Velho-RO
}

\author{
'Violencia y Vulnerabilidad: Espacios Vivenciados en la Unidad de \\ Internamiento Socioeducativo para Adolescentes en Porto Velho-RO
}

\author{
Elisangela Ferreira Menezes \\ Universidade Federal de Rondonia, Brasil \\ elis.86.pv@gmail.com
}

\section{Resumo}

O artigo faz uma análise sobre um estudo de caso realizado em 2010, na Unidade de internação feminina de Porto Velho, Estado de Rondônia. Essa unidade atende meninas que cometeram ato infracional e estão em medidas socioeducativas. Por meio deste trabalho, buscamos evidenciar a situação de vulnerabilidade dentro dos espaços prisionais, caracterizada, neste caso, pela unidade de internação. Como aporte teórico de análise será abordado os conceitos de espaço, gênero e desvio inter-relacionado com os estudos que abordam a violência e a criminalidade. A partir dessas considerações, o estudo pauta a compreensão da realidade das adolescentes em conflito com a lei.

Palavras-Chave: Espaço; Relações de Gênero; Adolescentes em Conflito com a Lei.

\begin{abstract}
This article analyzes a case study performed in 2010 in a female detention unit in Porto Velho, State of Rondonia, Brazil. This unit receives girls who have committed offences and are doing time under educational measures. Through this article, we seek to highlight situations of vulnerability found inside prison spaces, characterized in this case by a juvenile detention unit. As a theoretical basis for the analysis, this study will address the concepts of space, gender and deviation, interrelated with studies on violence and crime. From these considerations, the study will present a view of the reality of the children who are in conflict with the law.
\end{abstract}

Keywords: Space; Gender Relations; Adolescents in Conflict with the Law.

\section{Resumen}

El artículo analiza un estudio de caso realizado en 2010 en la unidad de internamiento femenina de Porto Velho, Estado de Rondonia. Esta unidad atiende a niñas que cometieron infracciones y están bajo medidas educativas. A través de este trabajo, pretendemos evidenciar la situación de vulenerabilidad dentro de los espacios carcelarios, caracterizados en este caso por la unidad de internamiento. Como aportación teórica, se abordarán los conceptos de espacio, género y desviación interrelacionados con los estudios que abordan la violencia y la criminalidad. A partir de estas consideraciones, el estudio pretende comprender la realidad de las adolescentes en conflicto con la ley.

Palabras-Clave: Espacio; Relaciones de Género; Adolescentes en Conflicto con la Ley. 
Violência e vulnerabilidade: espaços vivenciados na unidade de internação socioeducativa para adolescentes em Porto Velho-RO

\section{A Violência entre Jovens e Adolescentes: Algumas Considerações}

De acordo com o Estatuto da Criança e do Adolescente-ECA, art.103 o ato infracional pode ser entendido por: "[...] conduta descrita como crime ou contravenção penal". O ato infracional cometido por um adolescente é considerado um ato ilícito ou uma contravenção penal, que significa um ato ilícito de menos importância que o crime e que só acarreta ao seu autor a pena de multa ou prisão simples (BASTOS, 1992). Estudos sobre a criminalidade apontam um grande aumento no número de adolescentes que se encontram em medidas socioeducativas.

No campo da ciência geográfica, o tema tem poucas abordagens, a violência urbana tem se tornando um fato de grande preocupação por vários agentes sociais. Estudiosos têm se debruçado em torno desse tema, de acordo com Adorno (et. al, 1999 apud CHIMIN JUNIOR, 2011), no Brasil a violência urbana apresenta quatro tendências: crescimento da delinquência urbana, emergência da criminalidade organizada, grave violação de direitos humanos e explosão de conflitos nas relações interpessoais. Dessa forma, esse fato pode ser visto em várias escalas espaciais, o tráfico internacional de drogas, a criminalidade urbana têm tomado proporções mundiais.

O fenômeno da violência nas grandes cidades acompanha os desdobramentos das décadas de 1960 e 1970 que ocorriam na Europa e América do Norte. Esse fenômeno chegou a ser retratado em vários filmes, destacam-se entre eles 'Laranja Mecânica', de Anthony Burgess, de 1962, traz consigo a problemática da época. 'Laranja Mecânica' é um dilema da juventude delinquente que se constrói a partir da sociedade dos anos 60 e 70 , nos países onde o desenvolvimento na cidade crescia em uma velocidade rápida e constante.
Diante desses desdobramentos, a violência urbana se espalhou, os/as adolescentes como parte desse tecido social também sofrem as transformações da modernidade, o termo adolescente é uma categoria socialmente construída (ARIES, 1973 apud CHIMIN JUNIOR, 2011), além disso, é um termo relativamente moderno. Segundo Dayrell (2003 apud CHIMIN JUNIOR, 2011), na sociedade moderna o jovem e adolescente é visto como um ser do futuro, alguém que ainda não é aquilo que deve ser, fase de liberdade que pode mostrar comportamentos exóticos de prazer e extravagância, e por fim o jovem é associado a uma fase de crise e distanciamento da família.

A partir disso os/as adolescentes passam a ser um importante sujeito para a sociedade. Com o advento da modernidade, o conceito de família tradicional modificou-se, os papéis sociais também foram alterados; mulher, homem, crianças e adolescentes passaram a ter funções específicas, logo, lhe são cobradas tarefas e responsabilidades.

O modelo de alto consumo de bens e serviços torna-se cada vez mais encantador e aglutina as mais variadas camadas sociais. Com o espaço familiar alterado, pelo fato de as famílias estarem segregadas, as referências também mudam, pais e filhos têm cada vez mais conflitos, tudo isso aliado a outros fatores gera um descompasso na trajetória do/da adolescente.

Destarte, os espaços estão cada vez mais segregados, a violência física e simbólica está cada vez mais próxima dos jovens, ademais, convivemos em um tempo de rapidez e descarte das coisas e das pessoas, padrões de consumo, ou seja, uma economia de mercado, onde o novo é valorizado e o passado descartado com muita rapidez. Ocorre o que Giddens (1991) chama de flexibilidade da vida social, uma ruptura entre a tradição e a modernidade que demonstra, entre outros fatores, a busca pelo 
prazer, realizações sentimentais e satisfações sensoriais. A busca por prazer a qualquer custo, em alguns casos, pode comprometer os compromissos com o bem comum. Os prazeres da vida moderna podem apresentar a individualidade exacerbada, acompanhada dos descompromissos sociais, pode ter reflexos diretos na família. Há uma construção social e simbólica que impõe características próprias nos adolescentes, assim:

A adolescência na nossa cultura é a idade na qual se representam ainda formas imaginárias do mais-gozar. Toda publicidade apela para o "sem limites" da vida adolescente, representado pela velocidade da moto, pela potência do aparelho de som, pela resistência do carro, pelo barato da cerveja e do cigarro, pelo corpo aeróbico e perfeito malhado nas academias e transformado em ícone sexual, objeto incontestável do desejo dos jovens, velhos e crianças [...] (KEHL, 2004, p.100).

A situação social e econômica contribui de forma imperativa na trajetória dos/as adolescentes e jovens, geralmente na vida de um jovem estão inseridos vários segmentos que se cruzam e separam-se entre si, esses elementos podem ser identificados como estruturadores sociais e que podem incluir gênero, etnia, idade, geração, condições econômicas e sociais e, para entender melhor esses elementos estruturadores, usaremos o conceito de interseccionalidade (CRENSAHW, 2002).

A escola e a comunidade próxima ao lar são espaços vivenciados diretamente pelo adolescente, porém, também constituem espaços diferenciados de acordo com os grupos hierarquizados, a instituição familiar ainda tem um papel importante na construção dos valores e estabilidades dos adolescentes e jovens. Nesse momento de mudança física e psíquica, os adolescentes precisam se sentir seguros, assim, os reforços dos laços emocionais e sociais são importantes estabilizadores nesse momento de mudança.

Convivemos em sua sociedade de grandes disparidades socioeconômicas, por isso temos uma grande separação entre ricos e pobres. Evidentemente que a relação da baixa renda com a baixa escolaridade e o pouco ou nenhum acesso aos meios de infraestrutura como: saúde, saneamento básico e educação provocam nesses jovens a baixa autoestima. Juntamente com as fragilidades dos laços sociais e familiares, contribui para que os jovens e adolescentes fiquem vulneráveis aos espaços urbanos cada vez mais violentos.

No que se refere ao gênero, que representa uma categoria de análise, dentro do contexto espacial, mostra que essa categoria sofre mudanças com a dinâmica da sociedade e, segundo a geógrafa MacDowell (2000a), a categoria gênero representa construções sociais sobre o ser homem e mulher em diferentes épocas e momentos históricos, essa variabilidade do ser homem e mulher é interpretada dentro de várias ciências, entre elas a Geografia, mostrando que as características das relações de gênero variam de um país para o outro, de uma época para a outra e também de escalas e espaços que envolvem as relações da vida cotidiana.

O papel do conceito gênero, interligado com a situação das adolescentes em conflito com a lei, é importante para compreender de que forma as meninas são vistas pela sociedade e também como elas se veem dentro dessa condição. Outro elemento importante a ser considerado é de que forma elas são tratadas nas unidades de internação, mas não só isso; como a adolescente enfrenta o 'mundo lá fora' após cumprir as medidas socioeducativas, o ato infracional, de que forma ela se vê e como é vista pela família, amigos, escola, igreja e outros grupos sociais. 
Esses estudos são de vital importância quando nos deparamos com um alto índice de reincidência nas unidades de internação, sem referências, sem amparo, sem tratamento a adolescente não consegue se distanciar dos vínculos com o desvio e, consequentemente, $\mathrm{o}$ ato infracional, muitas vezes o vício de drogas e álcool, dificulta ainda mais a retomada da adolescente ao vínculo social.

É nesse sentido que nos orientamos por fazer uma breve análise da situação de uma unidade de internação para adolescentes do sexo feminino, com esse estudo de caso buscamos identificar as fragilidades presentes nesse sistema, apesar de não ter sido permitido o acesso às adolescentes internadas por questões internas da própria unidade. Resolvemos relatar o que observamos no campo de pesquisa, inclusive a dificuldade de acesso às informações da própria Unidade.

Com esse artigo temos o objetivo de fazer um breve relato da pesquisa de campo articulando elementos da realidade de uma Unidade de Internação de adolescentes do sexo feminino e com os conceitos sobre gênero, interseccionalidade, espaço e desvio. Contudo, apesar de poucas informações colhidas no campo, realizamos um comparativo da situação em que se encontram as adolescentes que estão em medidas socioeducativas em Porto Velho e o que prevê no Estatuto da Criança e do Adolescente, assim como o SINASE. Dessa forma, observamos em que medida as adolescentes estão em situação de vulnerabilidade em seu espaço social dentro e fora da Unidade de Internação.

\section{Referencial Teórico e Metodológico}

$\mathrm{Na}$ unidade de internação, há uma grande separação entre a adolescente e a sociedade, a relação é fria e superficial entre indivíduo e o Estado. Com isso, sinalizamos um conceito que caracteriza a unidade de internação como uma instituição totall e, como se refere Goffman (1974), é produto de resultados de conflitos familiares e corresponde a um lugar de segregação e tristeza sentidas diariamente pela adolescente. Este pode ser caracterizado como o espaço do medo, evidenciado por Tuan (1980) como a topofobia, um lugar não desejado que produz medo e insegurança, ou seja, a aversão a determinados lugares. As construções dessas percepções estão atreladas a uma construção simbólica dos lugares. De modo que, esse sentimento topofílico pode ser sentido tanto pela adolescente como para sua família.

A unidade pesquisada localiza-se no município de Porto Velho e atende meninas que cometeram infracional, conforme o art.103 do ECA. O trabalho se dá em um estudo de caso que foi realizado mediante cinco visitas a unidade de internação para infratoras do sexo feminino, houve também três entrevistas com a equipe técnica formada por socioeducadoras, psicólogos e diretora da Unidade.

As visitas foram concedidas pela Diretora da Unidade com a condição de não entrevistar as adolescentes internadas, não tirar cópia de nenhum documento da unidade, não fotografar nem gravar nenhum diálogo dentro da Unidade. De modo que o nosso trabalho se deu em observar e anotar no caderno de campo o que considerávamos importante. Foi realizado o levantamento de dados das adolescentes que deram entrada na Unidade do ano de 2010 e 2011. Em primeiro momentos, observamos que a unidade não tinha informações suficientes das adolescentes que davam entrada na Unidade.

No contexto histórico do atendimento socioeducativo até 1850 , os adolescentes eram submetidos às mesmas penas dos adultos, em 1927 foi promulgada o Decreto de 1.7043 que instituiu o código de menores, em 1979 foi implantado o novo Código de 
Menores que substituiu o anterior, sobretudo com poucas mudanças. Sobre o código de menores, Arantes descreve:

Pela legislação que vigorou no Brasil de 1927 a 1990, o Código de Menores, particularmente em sua segunda versão, todas as crianças e jovens tidos como em perigo ou perigosos (por exemplo: abandonado, carente, infrator, apresentando conduta dita antissocial, deficiência ou doente, ocioso, perambulante) eram passíveis, em um momento ou outro, de serem enviados às instituições de recolhimento. $\mathrm{Na}$ prática isto significa que o Estado podia, através do Juiz de Menor, destituir determinados pais do pátrio poder através da decretação de sentença de "situação irregular do menor". Sendo a "carência" uma das hipóteses de "situação irregular", podemos ter uma idéia do que isto podia representar em um país, onde já se estimou em 36 milhões o número de crianças pobres (ARANTES, 1999, p. 258).

Temos diante dessa consideração de Arantes, um dado social de que a maioria das crianças e adolescentes que era "recolhida" para o sistema socioeducativo era pobre. Com isso, podemos observar que durante o período de 1927 a 1990, a sociedade, de um modo geral, passava por grandes transformações, sendo elas econômicas, sociais e culturais. Essas transformações trouxeram consigo uma variedade de consequências que também atingiram as crianças e os jovens. $\mathrm{O}$ avanço da tecnologia, aliado à globalização, aumento do consumo, o individualismo, a crise nos papéis dentro da família trouxeram inúmeras dúvidas e incertezas do futuro dessas gerações. Temos em nossos dias atuais uma clara e grave dificuldade de reforçar os vínculos entre as gerações (BELARDINELLI, 2007). Por isso, não somente o valor econômico foi um fator determinante nesses processos, mas os valores sociais mudaram dentro de um contexto chamado modernidade.

Diante de vários questionamentos sobre o Código de menores, foi então articulado a criação de uma lei que assegurasse os direitos da criança e do adolescente, dessa forma, em 1990 foi criado o Estatuto da Criança e do Adolescente (ECA), sancionado pelo então Presidente Fernando Collor, com o objetivo de considerar a criança e adolescente como cidadão e sujeito de seus direitos, dando a eles um tratamento baseado na cidadania e assegurando a proteção legal dos seus direitos e da integridade física e mental.

O ECA, além de assegurar o direito da criança e do adolescente, regulamenta as medidas socioeducativas que prevê no Art. 90: “As entidades de atendimento são responsáveis pela manutenção das próprias unidades, assim como pelo planejamento e execução de programas de proteção e sócioeducativos destinados a crianças e adolescentes, em regime de: I - orientação e apoio sócio-familiar; II - apoio sócioeducativo em meio aberto;III - colocação familiar; IV - abrigo;V - liberdade assistida;VI - semi-liberdade; VII internação". As condições de internação devem seguir obrigações previstas no artigo 94 do Estatuto, dentro desse contexto observamos na pesquisa algumas condições que estavam contrárias ao Estatuto como: VII - oferecer instalações físicas em condições adequadas de habitabilidade, higiene, salubridade e segurança e os objetos necessários à higiene pessoal; VIII - oferecer vestuário e alimentação suficientes e adequados à faixa etária dos adolescentes atendidos.

O Sistema Nacional de Atendimento 
Violência e vulnerabilidade: espaços vivenciados na unidade de internação socioeducativa para adolescentes em Porto Velho-RO

Socioeducativo (SINASE)2 é um forma de integrar as políticas públicas para $\mathrm{O}$ atendimento e melhorar as condições ao adolescente e criança em condição de ato infracional, assim a importância e objetivo da construção do SINASE de acordo com a Secretaria Especial dos Direitos Humanos Brasília-DF- CONANDA, 2006:

O SINASE, enquanto sistema integrado articula os três níveis de governo para o desenvolvimento desses programas de atendimento, considerando a intersetorialidade e a co-responsabilidade da família, comunidade e Estado. Esse mesmo sistema estabelece ainda as competências e responsabilidades dos conselhos de direitos da criança e do adolescente, que devem sempre fundamentar suas decisões em diagnósticos e em diálogo direto com os demais integrantes do Sistema de Garantia de Direitos, tais como o Poder Judiciário e o Ministério Público (SINASE, 2006).

Apesar das propostas de integração entre as políticas do SINASE, o diálogo entre o os setores do governo e a sociedade tem um lacuna que dificulta a efetivação de ações e busca a transformação da realidade atual, entretanto, a realidade da Unidade pesquisada mostra em alguns aspectos o contrário do que prevê o ECA e SINASE.

A evidenciar as diretrizes do ECA e SINASE, percorremos um caminho teórico para dar bases de análise de documentos da Unidade, o ECA e o SINASE, utilizamos uma abordagem qualitativa e usamos como técnica a observação participante por entender que a pesquisa necessitava de buscar uma relação mais estreita entre pesquisador e pesquisado, entender e explicar as sociedades, suas instituições e suas relações (BORGES, 2009).
Empregamos estudo3 de caso como uma ferramenta metodológica para o desenvolvimento de pesquisa.

Foi utilizada a entrevista semiestruturada4 com as socioeducadoras da Unidade de internação, com a psicóloga, com a enfermeira e com a Diretora da Unidade. A real situação em que se encontram as meninas que cometem atos infracionais mostram que a condição de vulnerabilidade em seu contexto socioespacial podem acarretar prejuízos ainda maiores para a sociedade, a ressocialização passa por vários conflitos e o estigma é criado na imagem da adolescente, os resultados apontam para os problemas da reincidência. A busca por corrigir os "erros" sociais parece ser uma saída enquanto a importância de buscar políticas de prevenção do ato infracional fica fragilizada. Dessa forma, fundamenta Casoy:

As unidades socioeducativas definem como seu objetivo principal e ideológico a reeducação e reintegração dos menores infratores na sociedade, mas na verdade garantem a desigualdade social, uma vez que etiqueta esses jovens como criminosos em sua comunidade, fora dela e, principalmente, deixando marcas indeléveis na formação de uma identidade criminosa, muitas vezes positivas dentre seus pares (CASOY, 2010).

As desigualdades são evidentes entre as populações em que falta estrutura econômica e social, onde os vínculos familiares são mais frágeis. O jovem infrator é visto, em primeiro momento, como criminoso, dessa forma, ele acaba por internalizar o preconceito. Em muitos casos a ressocialização do indivíduo é delicada e conflituosa, principalmente quando se trata de um/a adolescente. E quando há envolvimento com drogas, a 
situação fica mais grave, o vício pode deixálos mais violentos. Por se tratarem de instituições totais, as unidades de internação carregam em si uma separação quase que total da sociedade. Esses espaços podem representar lugares, podem representar a solidão, o abandono, a dor da separação com a família. Nesse caso:

A prisão é um espaço que gera tristeza, paixões e revolta, tanto dentro como fora de seus muros. (...) O cárcere é uma instituição totalizante e despersonalizadora, onde a violência se converte em um instrumento de troca, em que prevalece a desconfiança e o único objetivo das pessoas é sair, fugir, atingir a liberdade. Essas características correspondem às prisões em geral (ESPINOZA, 2002, p. 52).

Como apontou a autora, a Unidade de Internação representa uma instituição do Estado que busca a ordem social, e promove ainda mais a degradação, pois o indivíduo fica totalmente separado da relação com sociedade.

\section{Relações de Gênero e Desvio 5}

Para fazer observações a respeito do trabalho proposto, devemos observar, a priori, as teorias sobre gênero que consideram os fatores das construções sociais e seus desdobramentos na sociedade. Sobre as considerações do conceito de gênero, observa McDowell (2000a, p. 31): "El sexo o diferencia biológica sería la estrutura básica em la que cada sociedade a lo largo de los distintos períodos históricos ha ido colgando distintas prendas, que son los os mecanismos socialmente definidos de las características de género".

Nesse sentido, observa-se que há uma diferenciação dos papéis construídos e consiste fora do conceito biológico que antes fora direcionado aos homens e as mulheres. Assim, Joseli Silva afirma que o conceito de gênero implica na análise temporal e espacial na configuração das relações sociais, evolvendo uma perspectiva relacional (SILVA, 2008).

A construção do espaço, bem como as relações humanas contidas nele, está submetida a relações de poder e dominação. Essa forma de olhar o gênero ${ }^{6}$ representa uma quebra de paradigmas científicos que desconsideravam as relações de gênero como fatores passíveis de estudo das ciências humanas.

Observando as considerações acima, Joseli Maria Silva propõe a construção de uma ciência que ela chama de "ciência subversiva". De tal modo, essa "subversão" para ela é compreendida de duas formas: a subversão na prática do saber científico e a subversão a partir das práticas de grupos sociais pesquisados que se encontram fora do centro das configurações do poder (SILVA, 2009, p. 14).

As epistemologias feministas podem elucidar novos discursos acadêmicos, a crítica de velhos conceitos, a visão androcêntrica do mundo levou a olhares semelhantes reproduzidos em teorias e metodologias científicas. Com isso, a postura subversiva enxerga a ciência como produto de construções sociais, passível de ser questionada e modificada. Por isso, os estudos das relações de gênero buscam modificar e reavaliar 'verdades inquestionáveis' da ciência, no discurso e na cultura.

A relação do conceito gênero com o espaço geográfico mostra que ambos se caracterizam por mudanças contínuas e, por isso, o tempo e o espaço são palco de suas representações.

$\mathrm{O}$ estudo sobre a mulher e o desvio na 
sociedade mostra que as direções das pesquisas estavam focadas em crimes como aborto, infanticídio e crimes passionais, a mulher estava sempre relacionada ao ambiente privado, sendo excluída do espaço público pelas mais variadas razões, ela ficou submetida à igreja, a ideologia da Tutela (ESPINOZA, 2002).

O discurso da Igreja sobre a mulher justifica-se pela sua suposta inclinação para o mal. A relação entre a mulher e o sistema punitivo se acentua e consagra na Idade Média, ressurgindo a meados do século XIX e intensificando-se durante todo esse período, que se estende até o final da Segunda Guerra Mundial (E. R. ZAFFARONI, op. cit, p. 21 apud ESPINOZA, 2002).

Nesse sentido, a tutela era necessária para manter a mulher no ambiente privado e controlar suas ações, fazendo com que ela esteja sempre tutelada, ou pelos pais na infância e adolescência, e depois pelo marido após o casamento. A necessidade da vigilância constante sobre a mulher se justificava pelo discurso de que a mulher era um ser fraco em corpo e inteligência, sendo ela produto de falha genética. Com relação à religiosidade o espírito da mulher seria fraco e tinha tendência para a sedução e carnalidade.

Dessa forma, a religião cristã e o Estado têm como função cuidar e vigiar a mulher (ESPINOZA, 2002). Assim como as mulheres, a ideologia da tutela estendeu-se também para os povos indígenas, negros, prostitutas, doentes mentais, crianças, adolescentes e outros; a repressão e descriminação representavam a lógica da colonização e serviam para justificar tais atos. Em especial, a mulher era vista como desviante quando exposta a certa liberdade, se fosse livre poderia cometer atos desviantes em sua conduta, o controle informal era uma boa arma de prevenção desses atos como aponta a autora:
No caso das mulheres, o sistema de controle por excelência tem sido o controle informal. Através de instâncias informais, como a família, a escola, a igreja, a vizinhança, todas as esferas da vida das mulheres são constantemente observadas e limitadas, dando pouca margem ao controle formal limite do sistema punitivo (materializado no cárcere). Essa situação gera uma menor visibilidade da mulher nos índices de criminalidade (ESPINOZA, 2002.p. 39).

Podemos perceber a reprodução de algumas dessas ações no contexto atual, o espaço é diferenciado para homens e mulheres, nesse processo de criação e recriação do espaço, a ideia de controlar e 'prender' a menina em casa parecem ser uma saída para que ela não seja exposta a ações 'erradas' ou desviantes. Nesse sentido, o espaço é vivenciado e sentido em diversas formas por homens e mulheres. Como forma de entender que o espaço geográfico não está somente atrelado ao espaço matemático, posto como sentido físico. Propomos o conceito de espaço vivido pelo geógrafo francês Armand Frémont (1980), esse espaço é uma experiência de vida que não acaba, mas está em constante movimento.

O espaço vivido é uma experiência contínua. (...) $\mathrm{O}$ espaço vivido é um espaço movimento e um espaçotempo vivido. (...) O espaço vivido é também, desde a mais tenra idade, um espaço social. (...) Mas temos de constatar que, se o espaço vivido acende às conceptualizações racionais da inteligência, ao raciocínio num espaço cartesiano e euclidiano, também se revela portador de cargas mais obscuras, 
Violência e vulnerabilidade: espaços vivenciados na unidade de internação socioeducativa para adolescentes em Porto Velho-RO

em que se misturam as escórias do afectivo, do mágico, do imaginário (FRÉMONT, 1980, p. 26-27).

As meninas que passam pela Unidade de internação vivenciam em seu espaço; símbolos, representações e elementos materiais e imateriais que cercam o seu cotidiano, alimentam um mundo de significações. As mudanças ocorridas no decorrer de sua vida fazem com que elas experimentem inúmeras sensações que vão desde a recordação de momentos agradáveis até a experimentação de uma vivência em espaços do medo, aflição e insegurança. $\mathrm{O}$ espaço vivido das meninas distinguiu-se dos espaços dos meninos, a participação em ambientes públicos é possivelmente mais limitada, continuamos nas considerações de Fremont (1980) sobre o espaço vivido:

No mesmo plano, o espaço vivido das mulheres distingue-se dos homens. (...) O espaço é constituído por um encaixe de células fechadas solitárias umas das outras, mas cuidadosamente distintas: a cidade, a casa, o quarto (...). As mulheres vivem em círculos muito estreitos, quase secretos, entre a casa familiar, o banho, algumas lojas vizinhas. Os homens acedem um espaço muito mais amplo (...) (FRÉMONT, 1980, p. 178).

Ademais, o espaço vivido pode estar associado a eixos que polarizam o poder, nessa trama identificam-se relações que se estruturam em um sistema de interconexão entre elementos característicos de certos grupos sociais. Dessa forma, trazemos o foco dessa questão no conceito de interseccionalidade que ajudam a compreender como essas subjetividades são reproduzidas no interior da sociedade.
A interseccionalidade é uma conceituação do problema que busca capturar as consequências estruturais e dinâmicas da interação entre dois ou mais eixos de subordinação. Ela trata especificamente da forma pela qual o racismo, o patriarcalismo, a opressão de classe e outros sistemas discriminatórios criam desigualdades básicas que estruturam as posições relativas de mulheres, raças, etnias, classes e outras. Além disso, a interseccionalidade trata da forma como as ações e políticas específicas geram opressões que fluem ao longo dos tais eixos, constituindo aspectos dinâmicos ou ativos do desempoderamento (CRENSHAW, 2002, p. 177).

Os eixos que se cruzam podem alimentarse das desigualdades existentes na sociedade, dessa maneira, ocorrem que nos espaços vividos pelas adolescentes, os eixos de poder descritos acima, podem influenciar em suas ações. Sem uma estrutura prévia, logo, sem educação, saúde, segurança, referências e valores éticos, vivendo em espaços marcados pela violência e discriminação pela cor e condição social, muitas internalizam com um sentimento de inferioridade diante de tais condições. Essa limitação cria o desempoderamento, não só entre as adolescentes, mas também em toda a família. Esse sentimento de ser inferiorizado e marginalizado pela sociedade provoca inúmeras consequências destrutivas para $\mathrm{o}$ individuo, que vão até o envolvimento com o crime; esse fato evoca para além de uma seriedade nas políticas públicas, mas um reconhecer de que a sociedade precisa rever seus valores éticos e morais.

Assim, podemos entender que a noção de interseccionalidade toma um olhar diferente, 
propõe uma analise das questões de gênero, etnia, classe e geração passa por uma ressignificação, nesses sistemas as condições de cada mulher e homem operam de formas diferentes, dependendo do lugar onde ela está posicionada, de fato as mulheres brancas experimentam reações discriminatórias diferentes das mulheres negras, gays, lésbicas que sofrem outros tipos de discriminação. Desse modo, dentro da Geografia, Valentine (2007) propõe que o conceito de interseccionalidade articula uma relação entre diferentes elementos identitários e o espaço, além de chamar a atenção para o fato de que raras vezes são usadas várias categorias juntas como gênero, classe, etnia, idade e sexualidade em um contexto social e espacial. Assim, o conceito pode ser utilizado na Geografia não só para compreender as interconexões do gênero em relação a outras identidades, mas também para o mapeamento de geometrias de opressão (ROSSI, 2011). Da mesma forma, Joseli Maria Silva enfatiza a importância do estudo da Geografia utilizando essa categoria de análise, pois enriquece e ajuda a entender melhor as redes conectas entre vários elementos e a posição dos sujeitos em uma determinada situação.

Com o advento da modernidade, é comum os espaços estarem mais limitados e segregados, casas com muros altos, condomínios fechados, a ideia de segurança e individualidade está cada vez mais comum. $\mathrm{Na}$ população carente, a realidade é um diferente, temos uma certa ideia de liberdade, pois as casas estão mais próximas, um das outras, as crianças e adolescentes estão mais juntas em alguns momentos reunidas em grupos. Porém, temos a tendência de que elas estão cada vez mais sozinhas, pois seus pais passam a maior parte do tempo fora de casa, com diversas ocupações. No caso das meninas há uma concepção sobre o espaço limitado a menina. Pelo fato de uma construção da imagem de que a menina, como um ser frágil, pode estar sujeita as tentações, as 'maldades' dos meninos, podem fazê-la algum mal, por isso os pais preferem que a filha fique em casa com intuito de protegê-la. Ao contrário dos meninos, que podem se 'virar sozinhos' e sabem se proteger dos outros. Assim, geração após geração repetem essas práticas, onde conferem a liberdade aos meninos e a limitação de espaços a menina. Possivelmente, esse fato explica a tendência aos poucos estudos sobre a criminalidade feminina. Por consequência, o fato de não avaliar as políticas que atendem a esse público específico.

\section{A Criminologia Feminista e o Sistema Punitivo}

Dentro da abordagem da criminologia feminista, temos duas tendências principais que referem-se à criminologia Positivista ou Tradicional e a criminologia Crítica ou da Reação Social. A Criminologia Positivista tem como abordagem tratando os atos desviantes como uma patologia social, defende que há indivíduos propensos biologicamente a cometer delitos, essa teoria privilegia o sentido etiológico, ou seja, as causas dos crimes. Os defensores dessa visão foram os teóricos Lombroso e Ferri e essas teorias foram defendidas por muito tempo pela ciência, criando as teorias eugênicas, contudo, a crítica apareceu e trouxe outras visões de estudo sobre o crime e desvio, sobretudo, as teorias de Durkheim na defesa do fato social e a anomia, conforme Ribeiro de Sá (2010, p. 8360):

(...) o autor argumentou e comprovou que o crime não é uma doença social, em si mesmo, embora o comportamento criminoso, em concreto, ou mesmo certas elevações, apresentadas pelas taxas de criminalidade, possam indicar 
uma patologia pessoal ou coletiva conforme se discutirá no desenvolvimento dessas reflexões. Com esta tese, É. Durkheim estava debatendo e polemizando com criminologistas de sua época, com destaque para os adeptos da Escola Penal Positiva, liderada pelo médico italiano Cesare Lombroso (18351909), defensores da explicação da criminalidade e do crime como fatos patológicos, ou seja, como passíveis de tratamento médico.

Dentro da visão da Criminologia Crítica, ou da Reação Social, a concepção sobre o crime como uma patologia é questionado, com o surgimento da Escola de Chicago no século XIX, prima-se por estudos sobre a sociologia do desvio que busca responder as condições dos processos de criminalização, e funda-se pelo paradigma da definição (ESPINOZA, 2002). As teorias interacionistas buscam a compreensão das interações sociais e a relação com o desvio e a criminalidade, os teóricos mais conhecidos da teoria interacionista foram Erving Goffman e Howard Becker. Ainda sobre esta questão, ponderamos que toda ação e interação social ocorre no espaço e no tempo, então, considera-se que o espaço e o tempo também devem ser levados em consideração na análise da realidade.

Ao buscar a compreensão das duas teorias com a pesquisa sobre desvio e ato infracional, observamos a relação das menores infratoras com o convívio no espaço social antes do ato infracional, podem ser consideradas as condições sociais, espaciais, econômicas e culturais em que estava inserida essa adolescente, e quando cumprindo medidas socioeducativas elas têm outra relação e convívio social; a Unidade de Internação. Nesse sentido, podemos perceber muitos casos em que a interação entre os indivíduos reflete comportamentos semelhantes, principalmente entre os jovens com poucas referências a serem seguidas.

A discussão sobre o desvio e o crime foi polemizada por vários teóricos, o alvo era mostrar de que forma a sociedade via o crime, se antes era visto como anormal, uma doença social em uma perspectiva positivista, agora estabelece que ótica do crime e do desvio esteja de acordo com as dinâmicas sociais, e está relacionado com as interações que o indivíduo tem com a sociedade. Assim, Miskolci, citando Foucault, coloca que "o denominou poder disciplinar, um meio de intervenção e normalização social que foi o responsável pela criação do desvio" (MISKOLCI, 2005, p. 53), o que é "certo" ou "errado" está sob o julgamento da sociedade criadora e determinadora das normas e regras sociais. Os grupos sociais desfavorecidos economicamente, socialmente e, em alguns casos, culturalmente, em sua maioria tornamse os "marginais" e são rapidamente taxados de criminosos, assim a:

A marginalização pressupõe um desvio em relação aos comportamentos - padrão, estabelecidos pelo grupo dominante (homem de meia idade, branco, e da classe média ou média alta) e que podem ser definidos enquanto conjunto de normas e valores que regulam os sistemas econômicos, social e político-administrativo (MALHEIROS, 1994, p. 119).

No caso das adolescentes, observa-se a distinção que a sociedade faz delas. Fora de um convívio social elas não oferecerão perigo. Nesse caso, o Estado que não oferece alternativas para muitos jovens condena uma boa parte dos indivíduos a uma vida de miséria e falta de recursos, sem educação, saúde e segurança, o Estado se dispõe a servir 
ao interesse de poucos que se mantêm no poder às custas de uma grande parte da população. Há uma exigência de produtividade na vida dos indivíduos que esmaga muitas crianças e adolescentes. Após o século XXI, os valores e a estrutura social passaram por várias mudanças, o papel da mulher na sociedade está mudando constantemente, o uso de drogas, bebidas alcoólicas, e várias outras formas de encarar a vida, podem gerar os mais variados conflitos.

\section{Unidade de Internação feminina de Porto Velho: Vivências e experiências}

Durante as visitas realizadas na Unidade, foi possível fazer um levantamento dos atos infracionais cometidos pelas adolescentes e, durante o ano de ano de 2010, foram 53 entradas de adolescentes, sendo 51 adolescentes liberadas da Unidade. No primeiro semestre de 2011, entre os meses de janeiro e maio, houve 13 entradas de adolescentes, a reincidência foi de 15\%, conforme o gráfico abaixo:

Com relação a tipificação dos atos, 65\% dos atos infracionais representam o tráfico de drogas e o furto. Durante a pesquisa, identificamos dois casos de homicídio - neste caso, as adolescentes estavam cumprindo pena de três anos de reclusão. $4 \%$, no ano de 2011 os dados vão até o mês de maio. O tráfico e o assalto qualificado representaram $30 \%$ das entradas na Unidade. O número de adolescentes do sexo feminino em medidas socioeducativas é menor em relação aos meninos. Entretanto, nos últimos anos vem aumentado o número de meninas infratoras no Brasil.

Notamos uma precariedade nas instalações destinadas aos adolescentes e crianças em situação de internação. As adolescentes internadas, ou mesmo as que ficaram em regime temporário, ficam em um lugar que não oferece condições para $\mathrm{o}$ seu

Figura 3. Demarcação simbólica do território.

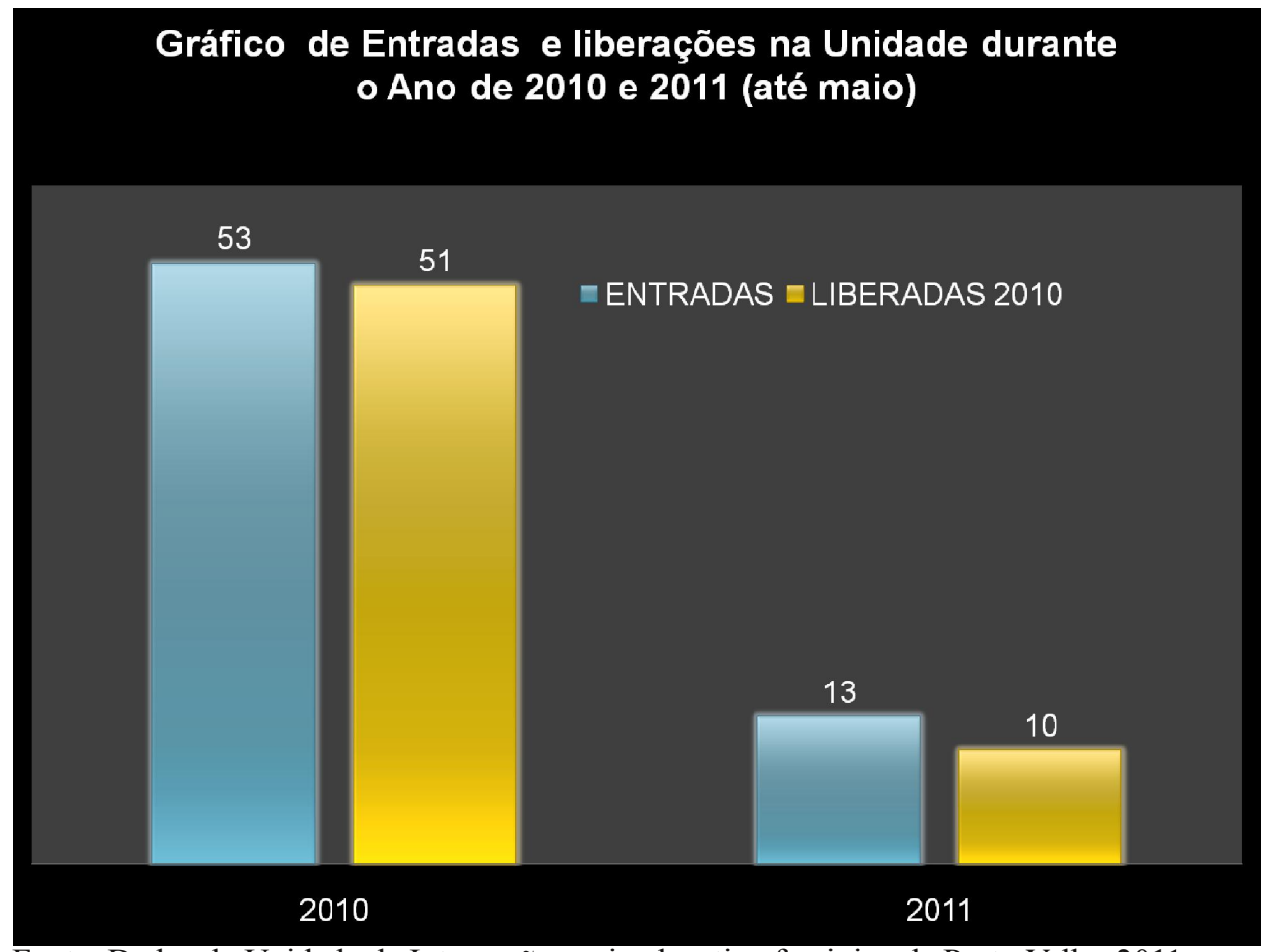

Fonte: Dados da Unidade de Internação socioeducativa feminina de Porto Velho-2011. 
desenvolvimento e possibilidade de voltar ao convívio saudável na sociedade, retomamos aí a questão do espaço do medo, a insegurança de ficar em um lugar que não oferece acolhimento.

A manutenção do local se dá, em parte, com o apoio familiar no acesso à vestimenta e produtos para a higiene pessoal. Entretanto, devemos ressaltar que a maioria das famílias não tem recursos financeiros suficientes para oferecer esses produtos, quando há casos de abandono familiar, a situação é ainda mais grave. Segundo relatos de uma socioeducadora, a mãe é quem, na maioria dos casos, se dispõe a dar o apoio a adolescente, no entanto, ela não tem muitos recursos e, em grande parte, falta conhecimento para lidar com essas situações. Os estudos mostram que esse fenômeno de famílias chefiadas por mulheres é cada vez mais comum (MACEDO, 2004), esses novos arranjos familiares traz consigo uma complexidade de situações no interior da família. Nesse caso, os próprios dados do Censo do ano 2000 (IBGE,2002) mostram que a cada quatro famílias brasileiras, uma é chefiada por mulher, além disso, outras pesquisas apontam para essa tendência, mulheres que estão no mercado de trabalho também são as únicas responsáveis pela manutenção da família. Ainda temos o fato de que a grande maioria delas sustenta a família com menos de 1,8 salário mínimo. Isso pode refletir em outro momento na constituição da análise, refere-se ao fato do acúmulo de responsabilidades das mulheres em geral, assim, a sobrecarga de trabalho é muito grande entre as mulheres, considerando um fator pouco abordado que é o trabalho doméstico. Assim, Borges (2004) coloca que, apesar das conquistas acumuladas pelas mulheres no século XX, com maior participação no mercado de trabalho e a escolaridade crescente, significou um acúmulo de funções em que o trabalho doméstico ainda fica por conta da mulher. Significa dizer que esse trabalho é indispensável para a manutenção da família, mas não é valorizado, nem remunerado.

Chegando nesse ponto, ressaltamos que muitas mães sofrem com essa sobrecarga de funções, muitas trabalham e cuidam da casa, são responsáveis pelo sustento da família. No momento em que saem de suas casas, seus filhos ficam desprotegidos, e passados os anos, muitos acabam caindo na criminalidade. Essa é uma realidade nas famílias, principalmente porque nestas famílias faltam bens básicos para a sobrevivência. Esses bens básicos podem ser os bens materiais e bens imateriais, como valores, referências e regras sociais.

Com relação à estrutura física do local, a Unidade foi uma adaptação de uma antiga casa, ou seja, não há lugar para lazer adequado e o lugar é muito escuro e abafado, não tem refrigeração e falta até mesmo o mínimo necessário para o trabalho da equipe técnica. Esta Unidade não está de acordo com que prevê o ECA no artigo 94: "VII oferecer instalações físicas em condições adequadas de habitabilidade, higiene, salubridade e segurança e os objetos necessários à higiene pessoal; VIII - oferecer vestuário e alimentação suficientes e adequados à faixa etária dos adolescentes atendidos". Observamos que essa não foi a realidade encontrada na Unidade pesquisada. O espaço não oferece atividades direcionadas a esse público e, segundo o SINASE, as condições físicas da unidade devem oferecer, entre outros: "Condições adequadas de higiene, limpeza, circulação, iluminação e segurança; Condições adequadas de repouso dos adolescentes; Salão para atividades coletivas e/ou espaço para estudo; Espaço e condições adequadas para visita íntima; Espaço e condições adequadas para visita familiar; Espaço com salas de aulas apropriadas contando com sala de professores 
e local para funcionamento da secretaria e direção escolar; Espaço para a prática de esportes e atividades de lazer e cultura devidamente equipados e em quantidade suficiente para o atendimento de todos os adolescentes; Espaço para a profissionalização".

O contato com a família é muito rápido e insuficiente para a obtenção de um bom resultado, em alguns casos a família abandona a adolescente. As relações familiares, nesse caso, encontram-se fragilizada e os pais, muitas vezes, abandonam as adolescentes. Não há cursos para a profissionalização das meninas, nem condições para que elas os façam em outro lugar, não há prática de esportes. Essas condições não garantem de forma nenhuma a eficiência do sistema socioeducativo. A segurança, tanto das meninas quanto da equipe técnica, é deficitária, um exemplo se deu enquanto realizávamos a pesquisa. Houve na unidade uma tentativa violenta de fuga, a qual colocou em risco não só a vida das adolescentes, mas todos os funcionários, estes vivenciava um clima de medo e insegurança.

As meninas vivem e experimentam as mais variadas situações nesse espaço de internação. Quando estávamos realizando a pesquisa, havia duas adolescentes que estavam cumprindo pena por homicídio; elas ficavam em quartos escuros e abafados e nossa experiência dentro do contexto da pesquisa nos permitiu a observação ${ }^{7}$ de várias como essas. Um dos espaços da unidade era estranho e confuso, ao perceber isso, perguntamos às servidoras que lugar era esse. Elas disseram que aquele espaço era destinado para quando as adolescentes chegavam pela primeira vez e, segundo as servidoras, o primeiro contato era bastante conflituoso, pois as meninas chegavam drogadas e muito agressivas. Por isso, ficavam pelo menos um dia sem ver a luz, sem ir ao banheiro e incomunicável. Passado esse momento elas, então, eram encaminhadas ao atendimento com a psicóloga.

Entre outros relatos, o que nos chamou a atenção foi que as meninas ficavam todas no mesmo quarto, isso possibilitava uma aproximação afetiva entre elas, de tal modo que era comum ocorrerem namoros e relações sexuais entre elas, as amizades e ciúmes também fazem parte de sua vida dentro da Unidade e, com isso, era comum acontecer algum conflito entre as internadas.

Nesses relatos acima percebemos a fragilidade da instituição e o pouco preparo da equipe profissional, somado às condições oferecidas às meninas internadas na unidade, falta de adequação de alguns itens para melhorar $\mathrm{o}$ atendimento socioeducativo $\mathrm{e}$ assegurar a sua volta da adolescente para casa de forma a superar os problemas com o desvio e o estigma criado sobre elas. A vida da menina acaba ficando marcada pela criminalização e seu convívio social fica prejudicado, principalmente pela falta de condições econômicas e sociais para seu desenvolvimento. A recusa da Direção da Unidade em dar mais informações relevantes na pesquisa mostra que o Estado esconde a real situação dos adolescentes infratores, não só em Porto Velho, mas em vários estados do país. O que ocorre nesses casos, ainda, é o abandono do Estado e a falta de zelo com os jovens e adolescentes na realidade atual. Pois, como prevê o próprio estatuto no Art. 125: "É dever do Estado zelar pela integridade física e mental dos internos, cabendo-lhe adotar as medidas adequadas de contenção e segurança".

A abertura da instituição para pesquisas acadêmicas é restrita. Na unidade de Porto Velho a permissão para conseguir realizar um trabalho profundo e critico sobre o tema foi prejudicada pelas restrições e burocracias do governo. Essa rigidez mostra o que o Estado 
quer esconder da sociedade a realidade vivida no espaço "socioeducador", em seus intramuros. Na verdade, esse lugar serve de depósito de pessoas, uma unidade sem condições de proporcionar a ressocialização da adolescente, constitui-se em uma representação de fracasso para a sociedade.

\section{Considerações Finais}

Neste artigo, foi possível tecer breves considerações sobre a Unidade de Internação para adolescentes de Porto Velho, RO. Dentro dessas considerações, observamos a necessidade de mais estudos sobre gênero e a criminalidade, com ênfase nos estudos sobre a juventude, visto que esse tema emerge de um problema da realidade social vivida e espacializada por muitas jovens no Brasil. Assim, paralelamente, foi posta uma realidade que pode servir como um espelho de situações vivenciadas em muitas Unidades de Internação no Brasil. Considerara-se, também, a importância da articulação entre várias disciplinas para análise de um mesmo tema, a Geografia, Sociologia, Psicologia, Criminologia e o Direito, abordando as relações de gênero. Ao aproximar-se com a categoria gênero, o tema ganha uma riqueza de detalhes que ajuda a entender os fenômenos que acontecem diferenciadamente entre meninos e meninas.

As correntes teóricas abordadas aqui foram desde considerar os estudos de gênero e seus desdobramentos na ciência principalmente na ciência geográfica - a criminologia feminista, a Escola Positivista da criminologia até a vertente interacionista e a abordagem da instituição total de Goffman; foi posto dividindo historicamente como a ciência compreendia o crime e o desvio, problematizou e modificou a forma de pensar seus conceitos. Aludindo a questão da mulher, percorremos a teoria positivista em que existiam tendências naturais e biológicas do corpo e do comportamento da mulher, isso coincidiu com $\mathrm{o}$ próprio pensamento cientifico da época e, posteriormente, viu-se que existia uma diferença entre sexo e gênero, levando a novos conceitos e quebra de paradigmas.

No contexto especificamente da violência, encara-se os entraves como um problema de responsabilidade do governo, mas observamos que, além desses problemas, enfrentamos graves situações de conflitos familiares geracionais, em que pais e filhos ainda não sabem lidar com tantos aparatos criados pela sociedade moderna. Cabe aqui ressaltar que as adolescentes não falaram conosco por impedimento do órgão e da delegacia, com isso, presumimos que uma instituição que propõe a reeducação e a ressocialização da jovem em conflito com a lei, deveria dar uma satisfação para a sociedade. Ao observarmos as condições físicas e os relatos da equipe da Unidade, nos referendamos as palavras de Espinoza, que discorre que o espaço prisional é um espaço de tristeza, revolta e despersonaliza os indivíduos, as pessoas são desconfiadas, têm medo de falar. Há um medo impregnado em toda a equipe, nas adolescentes, as pessoas que ficam ali internalizam ao que parece sutil, mas revelam características comuns nas prisões de um modo geral.

Em relação aos mecanismos para promover os direitos da criança e do adolescente, o ECA e o SINASE colaboram, porém, não resolvem $\mathrm{o}$ problema. $\mathrm{A}$ instituição socioeducadora, na verdade, não promove a educação, mas a segregação e o estigma sobre a adolescente, assim a:

A perversidade do sistema criminal se estabelece através do "aparato de publicidade" do Estado que projeta a ilusão de um poder punitivo igualitário, não seletivo, não discriminador, disfarçando de 
conjuntural ou circunstancial aquilo que é estrutural e permanente (inerente ao próprio poder). Se a este fato somarmos a tendência das pessoas em querer solucionar problemas complexos via a injeção de remédios de curto prazo, chegaremos a acreditar que o sistema penal resolverá as graves crises sociais de nosso tempo: desemprego, miséria, violência, entre outros (ESPINOZA, 2002, p. 36).

Aspectos sociais e econômicos e outros aspectos estão ligados ao desenvolvimento do indivíduo na sociedade, contudo, os aspectos culturais são amplamente aceitos pela ordem social, por isso o modo de educar atende também a essa premissa, a menina e o menino passam por esses processos de educação ligados às construções sociais, onde a cultura tem um papel determinante. Essa relação entre o desvio e as relações de gênero comporta as formas culturais de ser homem e mulher e se expressam também nas formas de desvio.

As crises sociais e os problemas dos atos infracionais e crime só poderão ser resolvidos com uma ampla política de inclusão social, não somente para as meninas, os jovens, de um modo geral, sofrem com as desigualdades e as injustiças sociais. Nesse sentido, é importante estabelecer relações entre as políticas do Estado e as condições morais e éticas de cada sociedade. Um plano que valorize a educação de qualidade e eficiente como um modo de socializar colocando as oportunidades a favor dos cidadãos e cidadãs.

1 Uma instituição total pode ser definida como um local de residência e trabalho onde um grande número de indivíduos com situação semelhante, separados da sociedade mais ampla por considerável período de tempo levam uma vida fechada e formalmente administrada (Goffman, 1974, p. 11). Disponível em: http://jus.com.br/revista/texto/1012/presidios-comoinstituicoes-totais-uma-leitura-em-erwinggoffman\#ixzz2D6nlg33Q

2 O SINASE é o conjunto ordenado de princípios, regras e critérios, de caráter jurídico, político, pedagógico, financeiro e administrativo, que envolve desde o processo de apuração de ato infracional até a execução de medida socioeducativa. Esse sistema nacional inclui os sistemas estaduais, distrital e municipais, bem como todas as políticas, planos e programas específicos de atenção a esse público (SINASE, 2006, p. 14).

$3 \quad[\ldots]$ de forma geral, o Estudo de Caso visa proporcionar certa vivência da realidade, tendo por base a discussão, a análise e a busca de solução de um determinado problema extraído da vida real. Em verdade, trata-se de uma estratégia metodológica de amplo uso, quando se pretende responder às questões 'como' e 'por que' determinadas situações ou fenômenos ocorrem, principalmente quando se dispõe de poucas possibilidades de interferência ou de controle sobre os eventos estudados (FIALHO e NEUBAUER FILHO, 2008, p. 452-1).

4 A entrevista semiestruturada possibilita um esquema básico, mas não é aplicado com rigidez pelo entrevistador, sendo possível fazer mudanças e adaptações (LUDKE; ANDRÉ, 1986).

5 A conduta desviante refere-a condutas socialmente caracterizadas, tudo que não está dentro do padrão de normalidade, " $\mathrm{O}$ crime, a prostituição, a vagabundagem, o alcoolismo,as ditas "perversões "sexuais eram apenas algumas das formas de classificação que podiam ser unificadas como anormalidade (MISKOLCI, 2005). Esta fazia parte da visão determinista destro das teorias biológicas.

6 O estudo da condição da mulher, através de uma ótica de gênero, representa a ruptura epistemológica mais importante dos últimos vinte anos nas ciências sociais. Sua importância reside justamente em romper com a invisibilidade da mulher nos estudos que enfocam a perspectiva masculina como universal e como protótipo do humano (visão androcêntrica). Esta linha de pensamento justificou-se sob os argumentos da inclusão tácita da mulher nas referências masculinas, e do excesso de especificidade na elaboração de estudos ou pesquisas desde um parâmetro exclusivamente feminino." A. Facio e R. 
Camacho, "En busca de las mujeres perdidas o una aproximación crítica a la Criminología", in Vigiladas y Castigadas. Lima: CLADEM, 1993, p. 30 apud Espinoza, 2002.

As internadas estavam dormindo, quando chegamos na Unidade, e assim elas ficavam grande parte do dia, quando perguntamos para a socioeducadora sobre elas, as respostas eram que as meninas estavam em um estado de depressão e não gostavam de conversar, estudar e às vezes nem mesmo de se alimentar.

\section{Referências}

ADORNO, Sergio; BORDINI, Eliana B.; LIMA, Renato S. de. O adolescente e as mudanças na criminalidade urbana. São Paulo em Perspectiva, v.13, n. 4, p. $62-$ $74,1999$.

ARANTES, Esther Maria. De "criança infeliz" a "menor irregular" - vicissitudes na arte de governar a infância In: JACÓ VILELA, Ana Maria; JABUR, Fábio e Rodrigues, CONDE, Hiliana de Barros. Clio - Payché: Histórias da Psicologia no Brasil. Rio de Janeiro: UERJ, NAPE, 1999, p. 257.

ARIES, Philippe. História social da criança e da família. Rio de Janeiro: Guanabara, 1973.

BECKER, Howard S.2008. Outsiders: Estudos de sociologia do desvio. Rio de Janeiro: Zahar, 1963.

BORGES. Maristela Corrêa. Da observação participante à participação observante: Uma experiência de pesquisa qualitativa. In: RAMIRES, Julio Cesar de Lima; PESSÔA, Vera Lúcia Salazar. (Orgs). Geografia e Pesquisa Qualitativa: Nas trilhas da investigação. Uberlândia: Assis, 2009, p. 183-198.

BASTOS, Maria Aparecida de. Direito da
Criança e do Adolescente. 1992.

BELARDINELLI, Sergio. A pluralidade das formas familiares e a família como insubstituível "Capital Social". In: BORGES, Ângela. Castro, Mary Garcia. (Orgs). Família, Gênero e Gerações: Desafios para as políticas sociais. $1^{\text {a }}$ Ed. São Paulo: Paulinas, 2007, p. $22-43$.

CASOY, Ilana. Sobre a Criminalidade Juvenil. Revista Sociologia: Desafios da Segurança Pública, v. 2, n. 31, p. 20 - 33, 2010 .

COHEN, A.K. A Delinqüência como subcultura. In: BRITO, S. (Org.) Sociologia da Juventude III. Rio de Janeiro: Zahar, 1968.

CRENSHAW, Kimberlé. Documento para o encontro de especialistas em aspectos da discriminação racial relativos ao gênero. Estudos Feministas, v.7, n. 12, p. 171 - 188, 2002.

DAYRELL, Juarez. O jovem como sujeito social. Revista Brasileira de Educação, n. 24, p. $40-52,2003$.

DURKHEIM, Emile. As Regras do Método Sociológico. São Paulo: Cia. Editora Nacional, 6a. Edição, 1972.

ESPINOZA, Olga. A Prisão feminina desde um olhar da criminologia feminista. Revista Transdisciplinar de Ciências Penitenciárias, v. 1, n. 1, p. 35 - 59, 2002.

FRÉMONT, Armand. A Região, Espaço Vivido. Trad. Antônio Gonçalves. Reivão \& Antônio G. Mendes. Coimbra: Livraria Almeida, 1980.

GIDDENS, Anthony. As consequências da 
Violência e vulnerabilidade: espaços vivenciados na unidade de internação socioeducativa para adolescentes em Porto Velho-RO

modernidade. São Paulo, Unesp, 1991.

GIL, Antônio Carlos. Como Elaborar Projetos de Pesquisa. São Paulo: Atlas, 2002.

CHIMIN JUNIOR, Alides Baptista. Espaço, vulnerabilidade e masculinidade de adolescentes em conflito com a lei. In: SILVA, Joseli Maria; ORNAT, Marcio Jose; CHIMIN JUNIOR, Alides Batista. (Orgs.) Espaço, Genero \& Masculinidades Plurais. Ponta Grossa: TodaPalavra, 2011, p. 55 124.

LIBERATTI, Wilson. Teoria da Subcultura Delinquente: Como surgem as gangues juvenis. Revista. Ciências Jurídicas, v. 6, n. 1, p. 271 - 307, 2008.

LUDKE, Menga; ANDRÉ, Marli E. D. A pesquisa em educação: abordagens qualitativas. São Paulo: Editora Pedagógica Universitária, 1986.

KEHL, Maria Rita. A juventude como sintoma da cultura. In: NOVAES, Regina; VANNUCHI, Paulo (Orgs). Juventude e Sociedade. SP: Instituto de Cidadania/ Ed. Fundação Perseu Abramo, 2004, p. 89 - 114.

MALHEIROS, Jorge Macaísta. Tendências Recentes na Geografia Social: $O$ estudo dos Grupos desfavorecidos. (s/d).

MERTON, Robert. Sociologia: teoria e estrutura. SP: Ed. Mestre Social, 1968.

MIKOLCI. Richard. Do desvio às diferenças. Revista Teoria \& Pesquisa, n. 47, p. $9-41$, 2005.

RAMIRES, Júlio César de Lima.(Orgs.) Geografia e Pesquisa Qualitativa: nas trilhas da investigação. Uberlândia: Assis,
2009.

RIBEIRO DE SÁ, Geraldo. O crime, a pena e o direito em Émile Durkhein. XIV Congresso Nacional do CONPEDI, 2010.

ROSSI, Rodrigo. Masculinidades e interseccionalidades na vivência de territórios instituídos por adolescentes em conflito com a lei. In: SILVA, Joseli Maria; ORNAT, Marcio Jose; CHIMIN JUNIOR, Alides Batista. (Orgs.) Espaço, Genero \& Masculinidades Plurais. Ponta Grossa: TodaPalavra, 2011, p. 125 - 192.

SENA, Isael de Jesus. Machado; Carvalho, Thiago Ribeiro; Coelho, Maria Thereza Ávila Dantas. A Delinqüiência Juvenil e suas Relações com a Função Paterna. (s/d)

SILVA, Joseli Maria. Geografias Subversivas: discurso sobre espaço, gênero e sexualidades. Ponta Grossa: Todapalavra, 2009.

TUAN, Yi-Fu. Topofilia, um estudo da percepção, atitudes e valores do meio ambiente. São Paulo, DIFEL, 1980.

VALENTINE, Gill. Theorizing and Researching Intersectionnality: A Challenge for Feminist Geografhy. The professional Geographer, v.50, n. 1, p.10-21, 2007.

\section{Sites}

http://jus.com.br/revista/texto/1012/presidioscomo-instituicoes-totais-uma-leitura-emerwing-goffman\#ixzz2D6nlg33Q $<$ Acesso em: 20/11/12>.

http://protagonismojuvenil.inesc.org.br/biblio teca/legislacao/ECA.pdf, $<$ Acesso em 06/07/2011>.

http://www.condeca.sp.gov.br/legislacao/sina se_integra.pdf <Acesso em 06/07/2011>.

Recebido em 22 de abril de 2014.

Aceito em 06 de setembro de 2015. 